\title{
An integrated water quality modelling framework for reporting on Great Barrier Reef catchments
}

\author{
R. Ellis ${ }^{a}$ and R. Searle ${ }^{b}$ \\ ${ }^{a}$ Department of Science Information Technology Innovation and the Arts, Queensland \\ Email: robin.ellis@science.dsitia.qld.gov.au \\ ${ }^{b}$ CSIRO Land \& Water, Brisbane
}

\begin{abstract}
The Paddock to Reef Modelling (P2R) and Monitoring Program reports on progress towards meeting the Reef Water Quality Protection Plan (Reef Plan) targets. The targets set out in the Reef Plan are designed to improve water quality entering the Great Barrier Reef (GBR) through improving land management practices. Catchment modelling is being used as one line of evidence to report on progress towards Reef Plan targets resulting from investment in improved management practices. The eWater Source Integrated Modelling System (Source IMS) was chosen as the preferred modelling platform for undertaking GBR water quality modelling. The main reason for choosing eWater source was its flexible architecture that enables users to write customised plug-ins to meet specific modelling requirements.
\end{abstract}

After a review of currently available modelling platforms, it was determined that there was no "off the shelf" software that could meet all of the modelling requirements. SedNet alone could not provide the finer resolution time stepping required, and Source IMS cannot inherently represent many variations of a spatially varying practice like cropping, to the level of detail required to allow subtle changes in management system to have a recognisable effect on model outputs.

To address these issues, and answer the questions being posed by policy makers, customised plug-ins for Source IMS were developed. These plug-ins allowed us to integrate the best available data sources and landscape process understanding into the catchment model. Purpose built routines enabling representations of processes such as the effects of temporally and spatially variable ground cover on soil erosion, aggregation of deterministic crop model outputs directly into the catchment model and the incorporation of SedNet gully and stream bank erosion algorithms were developed. Additional reporting tools were also written to enable rapid interrogation of model outputs. For example, reporting of pollutant loads by subcatchment, landuse, process (gully, streambank, hillslope) for any time period from daily to average annual.

The development of the GBR Source Catchments models demonstrates the highly flexible nature of the Source IMS framework. With flexibility also comes a tendency towards ever increasing complexity. As more involved questions are posed, it is tempting to keep adding to the functionality of the model. Although the modelling framework is capable of supporting complex algorithms it is essential that these are also supported by observed data and understanding derived from experimentation.

Keywords: $\quad$ Source Catchments Integrated Modelling System, Water Quality, Great Barrier Reef 
Ellis, R and Searle R., An integrated water quality modelling framework for reporting on Great Barrier Reef catchments

\section{INTRODUCTION}

The Reef Water Quality Protection Plan (Reef Plan) is a joint commitment of the Australian and Queensland Governments to minimise the risk to the Great Barrier Reef ecosystem from a decline in the quality of water entering the reef from adjacent catchments (Reef Water Quality Protection Plan Secretariat, 2013). The Paddock to Reef (P2R) Modelling and Monitoring Program reports on progress towards meeting Reef Plan targets (Carroll et al., 2012). Climate variability, limited resources and lack of a long term water quality monitoring data prevents us relying solely on measured data to assess progress towards specified targets. Catchment modelling is being used to quantify water quality trends resulting from investment in land management.

The steady state catchment scale water quality model SedNet (Prosser et al., 2001) has been used widely in Australia to estimate the long term annual average generation of sediment and nutrients from landscapes and their delivery to receiving waters. The SedNet model has been used previously in the GBR catchments to model the generation and transport of pollutants (Cogle et al., 2009). The fundamental processes represented in SedNet, such as the representation of key sediment generation processes (hillslope, gully and stream bank), provide a sound conceptual platform to develop complete catchment pollutant budgets. Such budgets help us understand the important spatial and biophysical interactions in a catchment controlling water quality. However, it is recognised that steady state modelling has limited utility for exploring complex interactions of climate, soils and land management, with the importance if these interactions (such as intense rainfall coupled with exposed ground surface) reported by Searle and Ellis (2009). Traditional steady state SedNet applications are unable to vary erosion model data inputs temporally, an important requirement when representing management practice changes through time. Newham et al. (2004) has also demonstrated the benefits of combining deterministic model components to simulate landscape processes at a fine time scale.

Recent improvements in catchment hydrology modelling frameworks and the natural evolution of desktop computing capacity, has led to the opportunity to build upon the solid conceptual foundations of SedNet's spatially explicit steady state approach. By applying the spatially explicit generation, transport and delivery concepts within a hydrology framework operating at a daily time step, incorporating temporally variable parameters, land and water managers will have access to a richer analysis of the complex interactions controlling catchment water quality (Searle and Ellis 2009). Understanding derived from such analyses can potentially improve investment prioritisation and give greater confidence in the catchment management decision making processes. Model predictions from a daily time step model are also able to be compared with observed water quality data that are typically representative of a point in time or an identified event. Comparison of predicted in-stream pollutant loads over these defined periods provides one technique for validating the water quantity model, a technique not available to steady state modeling.

This paper will present an example of the application of SedNet conceptual framework within a daily time step water quantity model implemented in eWater's Source Integrated Modelling System (Source IMS) (Welsh et al., 2013) for the Great Barrier Reef catchments. In addition to SedNet's generation and delivery component models, the GBR application also utilises the flexible modelling framework of Source IMS to incorporate pollutant generation estimates from robust agricultural production system models. The point scale models HowLeaky? (Rattray et al. 2004) and APSIM (Keating et al., 2003) are used to model pollutant generation from agricultural industries recognised as critical contributors to the GBR loads of nutrients and pesticides. They allow explicit representation of the collection of management options available to a farmer such as crop rotations and planting, tillage and nutrient and herbicide applications. A point scale grazing model (GRASP, Littleboy and McKeon 1997) was also used to provide mechanisms for altering sediment generation processes when representing management changes across broad areas.

A further extension of Source IMS' flexible architecture is exhibited by the parameterisation and reporting tools that have been specifically built to assist modellers in establishing, running and interpreting what have become extremely complex catchment scale water quality models. 
Ellis, R and Searle R., An integrated water quality modelling framework for reporting on Great Barrier Reef catchments

\section{STUDY AREA}

The Great Barrier Reef catchments make up some 420,000 $\mathrm{km}^{2}$, and extend from the northern tip of Cape York to the Wide Bay region near Fraser Island, Queensland. The northern wet tropics experience near monsoonal conditions throughout the wet season (typically over the summer months of December - February) with annual average rainfall in excess of $3000 \mathrm{~mm}$. In contrast, much of the western area of the GBR catchments receive considerably less rainfall, with Emerald receiving $<600 \mathrm{~mm}$ of rain annually.

Depending on access to reliable water, broad scale cropping of grains, cereals, and cotton occurs throughout significant pockets of the inland catchments. Where cropping isn't sustainable, grazing of beef cattle is the dominate land use. In coastal zones, particularly where large flood plains and deltas have formed, the sugarcane industry has a significant foot print. Scattered throughout the GBR catchments are also many mining enterprises, some significant areas of urbanisation and other industries such as dairy and horticulture.

The river systems flowing to the GBR are as varied as the topography and climate. Streams in the west of the catchment are typically ephemeral, whilst coastal catchment streams tend to flow perennially. Some of the rivers are highly regulated to support urbanisation and agriculture whilst other rivers are relatively unaffected by human activity.

\section{MODEL REQUIREMENTS}

The main purpose of the model is to inform stakeholders and policy makers about the efficacy of land management changes over a long period of time. Thus, there are a number of fundamental requirements the modelling system must satisfy including,

- $\quad$ provision of adequate simulation of hydrologic and biogeochemical process under current and future management conditions, to allow realistic simulation of a range of land management scenarios,

- $\quad$ estimation of mass balance budgets for a broad range of pollutants,

- $\quad$ it must be spatially and temporally explicit (allowing the ability to validate in-stream model load predictions with sporadic and temporally variable monitored data),

- $\quad$ it must be readily repeatable, and model outputs must be comprehensive, yet readily interpreted.

\section{METHODS}

\subsection{Source Catchments software}

Source IMS is built on the general purpose modelling framework TIME (Rahman et al., 2003). Source IMS is designed as a plug-in driven architecture where functionality in the form of purpose written model components are plugged in to the framework to extend the core functionality. The provision of additional component models via plug-in makes the Source IMS modelling framework extremely flexible, and is the primary reason that this framework was selected to represent the complex pollutant generation and in-stream processing required for the GBR application.

In conjunction with a robust water quantity modelling 'engine', Source IMS comes with a range of pollutant generation and in-stream processing component models that can be applied to relevant Functional Units (FUs) and transport links. In addition to the standard generation and transport component models provided "out of the box", the Source IMS modelling framework provides standard software interfaces exposing relevant internal state variables at all of these important sub component model elements. This allows for purpose built model code to be easily incorporated into the framework. 
Ellis, R and Searle R., An integrated water quality modelling framework for reporting on Great Barrier Reef catchments

\subsection{The GBR Model Architecture}

To meet the project requirements a purpose written suite of software model components was created to plug in to Source IMS. This plug-in, referred to as "Dynamic SedNet" (with additions specific to GBR modelling), provides components to model the conceptual catchment processes required. The model calculates mass balance budgets for 2 sediment, 6 nutrient and 8 pesticide pollutants. Whilst many land uses are represented by the FUs in the model structure, of most importance are cropping and grazing land uses. The core landscape and stream processes that are represented in the model include rainfall and runoff, hill slope generation, gully generation, overland filtering, stream bank erosion, in-stream processing, flood plain deposition, stream deposition, reservoir deposition and stream transport (Figure 1).

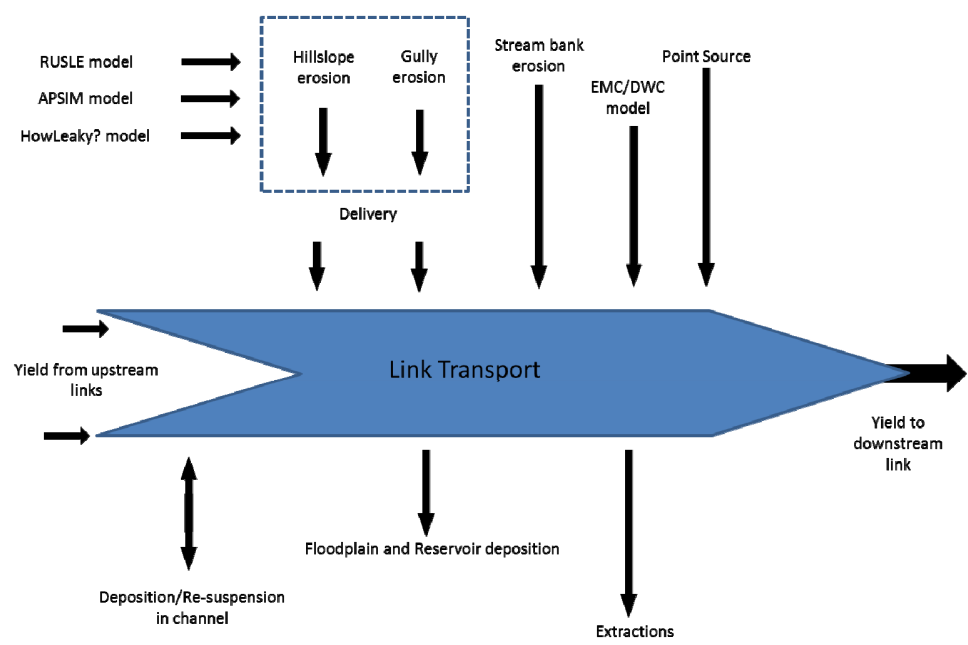

The complexity of land

Figure 1. Conceptual diagram of "Dynamic SedNet" processes. management, climate and soils interactions in cropping systems is not readily representable within a Source IMS project covering an entire GBR catchment. To incorporate this complexity, an integrated modelling approach was used where the

Table 1. Model components used to generate inputs for the catchment scale modelling for each pollutant. EMC refers to a steady state empirically derived concentration approach to pollutant generation.

\begin{tabular}{lll}
\hline Pollutant & Cropping & Grazing \\
\hline Sediment (Coarse \& Fine) & APSIM/HowLeaky & SedNet \\
Particulate Nitrogen & $\mathrm{f}$ (Sediment) & $\mathrm{f}$ (Sediment) \\
Dissolved Inorganic Nitrogen & APSIM/EMC & EMC \\
Dissolved Organic Nitrogen & EMC & EMC \\
Particulate Phosphorus & $\mathrm{f}$ (Sediment) & $\mathrm{f}$ (Sediment) \\
Filterable Reactive Phosphorus & HowLeaky & EMC \\
Dissolved Organic Phosphorus & HowLeaky & EMC \\
Pesticides & HowLeaky & EMC \\
\hline
\end{tabular}
paddock model most suited to a given land use and/or pollutant was applied. Table 1 lists these pollutants and the general modelling paradigm used to represent generation, with details on model choice in Shaw et al. (2013). Specific utilities were provided to accumulate the relevant outputs from APSIM and HowLeaky? into a single pollutant load time series representing the land management, climate and soils interaction for each FU. These time series are imported to the Source IMS project, thus transferring the complexity from paddock scale to the catchment scale model. This gives the ability for the Source IMS to represent changes pollutant generation from cropping enterprises via scenario analysis when small but specific management changes need to be considered.

SedNet style sediment generation in grazing lands utilises a daily time step version of the Revised Universal Soil Loss Equation (RUSLE) (Renard et al. 1997). Key to the operation of this within the Dynamic SedNet environment is the supply of spatially and temporally variable estimates of "C-factor" (related to ground cover), for which repeated spatial analyses are performed to provide a time series input of topographic and 
Ellis, R and Searle R., An integrated water quality modelling framework for reporting on Great Barrier Reef catchments

ground cover variables for each instance of grazing in the Source IMS model. To allow representation of the adoption of improved management practices, the $\mathrm{C}$-factor input layers were manipulated according to the relationships derived from analysis of simulations provided by a deterministic, point-based native pasture model, GRASP (Littleboy and McKeon 1997). For each of the climate/land type scenarios identified by Whish (2012), 15 utilisation rates were modelled using GRASP to represent the range in management options. Management practice systems in grazing were defined through an ABCD framework (Carroll et al. 2013). This practice framework specified requirements for the maximum acceptable utilisation rates for the maintenance of perennial pasture species and average cover levels. The maximum acceptable utilisation rate varies across the range of land types and rainfall conditions, with higher utilisation possible in wetter locations and lower utilisation possible in dry locations. The GRASP simulations were reviewed with these rules in mind to assign them into $\mathrm{A}, \mathrm{B}, \mathrm{C}$ or $\mathrm{D}$ level management. The relationship between management steps, e.g. $\mathrm{C}$ to $\mathrm{B}$, was then derived through linear regression of cover outputs on a monthly basis for each land type after pooling across climate stations.

The C-factor layer manipulation was applied under a spatial 'mask' of theoretical management change distribution, based on a history of cover changes on generalised farm areas (Bastin 2012). RUSLE time series input variables were re-calculated, informing the Source IMS model of changes in grazing land management.

\subsection{Software Enhancements}

Bespoke model components were coded and plugged into the framework to provide alternative representations of these processes. Purpose built models were coded in C\# to meet the specific modelling needs, particularly those elements representing the SedNet conceptual landscape processes.

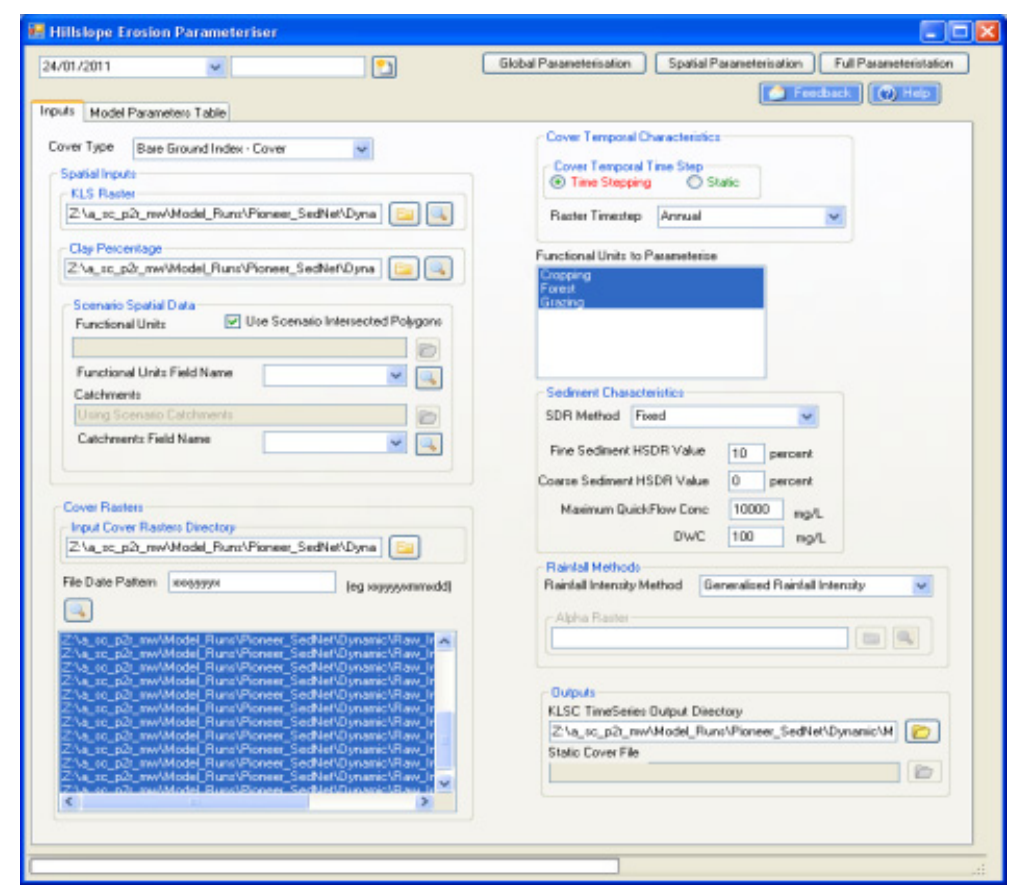

Figure 2. Example of purpose built model parameterisation form to aid in efficient and accurate parameterisation of the GBR catchment model. This utility is used to set up the processing of ground cover rasters to generate and assign parameters to relevant sub-models within the GBR modelling framework. As well as creating
process models, a
range of ancillary
components were
implemented to assist
in model
parameterisation and
reporting. Given the
complexity of the
processes being
represented and the
number of parameters
required to support the
modelling of the 16
constituents, these
supporting tools are
critical. The Source
IMS framework
provides only
is increased. The
purpose built
functionality and can
become cumbersome
as model complexity
is antary

parameterisation modules allow for repeatable, efficient and accurate parameterisation of all component models (Figure 2), often performing tasks like repetitive spatial analyses and importation of times series files from external models. 
Ellis, R and Searle R., An integrated water quality modelling framework for reporting on Great Barrier Reef catchments

Similarly, Source IMS only has limited reporting functionality "out of the box". A range of specific reporting tools were implemented that integrated with the modelling workflow and were tailored to project reporting requirements (Figure 3). These tools write required model outputs to file for subsequent use and analysis, and also present summarised tables to the user that can be dynamically filtered. Model inputs and outputs are able to be viewed in a spatial context, with a SedNet style 'contribution' tool.
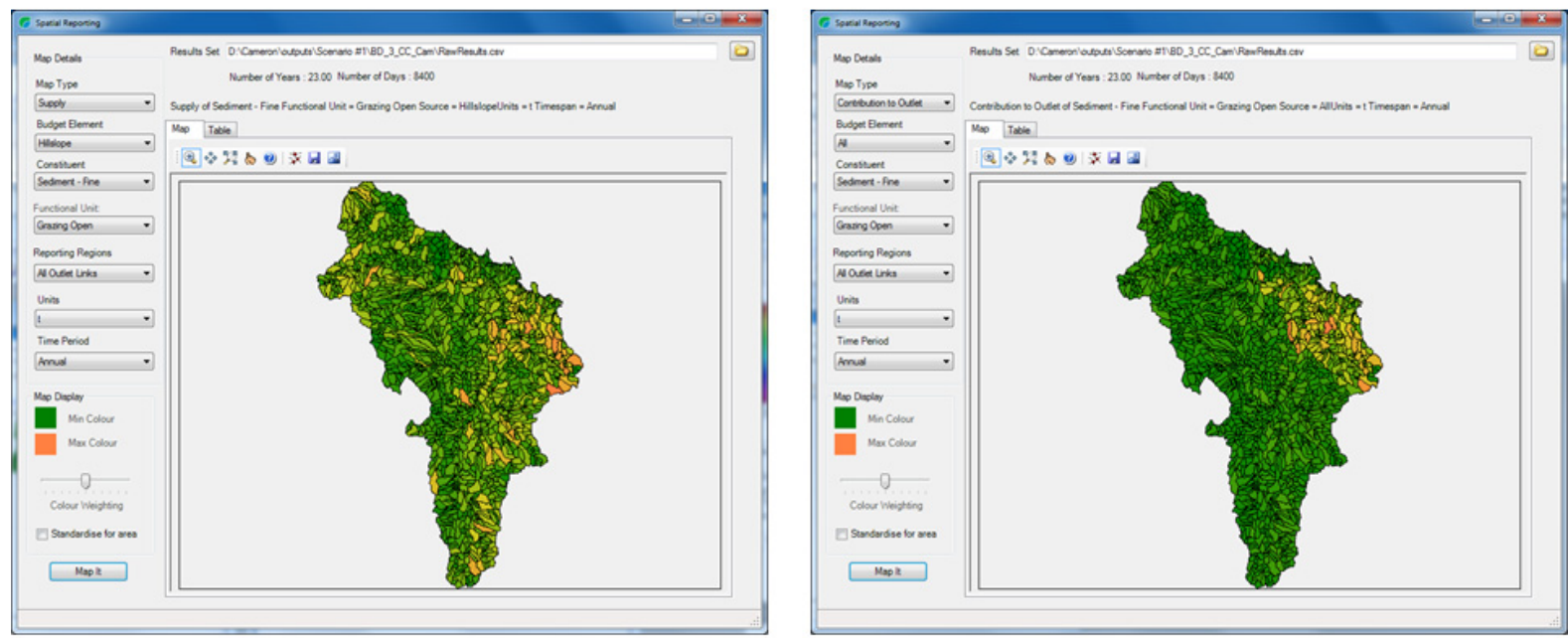

Figure 3. Example spatial results viewer showing both supply to the stream network and GBR export contribution of fine sediment.

\section{DISCUSSION}

The Source IMS provides a powerful and flexible environment for catchment water quality modeling. The ability to modify the software to suit a range of modelling and reporting requirements was critical to the success of the Paddock to Reef modelling program. The ability to develop a total landscape pollutant budget at a fine time scale is a powerful tool upon which to develop an agreed understanding of landscape dynamics. The fine timescale of the modelling framework allows for climate variability to be accounted for and objective analysis of longer term trends to be undertaken.

The flexible architecture of Source IMS has allowed us to apply the most appropriate pollutant generation sub-models to the individual land uses within the catchment. By incorporating concepts encapsulated in the deterministic cropping systems models across the more intensive land uses, we were able to deliver more effective analysis of the dynamics of these complex systems. Where our knowledge and understanding of particular land management systems was not as comprehensive, we have used less complex empirical models. Additionally, the purpose built parameterisation routines for hillslope, gully and stream bank erosion have allowed for the spatial variability of SedNet to be emulated in the 'lumped' conceptual structure of Source IMS. The inclusion of SedNet-style generation models means the perpetuation of some features that are not attractive to all applications, such as the reliance on 'sediment delivery ratios' and other crude adjustment factors. As with all models, it is important that these limitations are understood by those utilising the model predictions.

With a broad range of stakeholders and clients relying on the modelling work in the GBR it was very easy to end up in a cycle of concurrent model development and application. This makes it possible to derive a very complex model that simulates beyond the appropriate use of the available data. The disaggregation of long term annual average algorithms (as used by SedNet) into a daily time step model also potentially compromises the robustness of the model and its predictions. Care must be taken to ensure that the desire for complexity does not result in a model design that breaches the assumptions of the algorithms and data inputs.

Ultimately the flexibility of the Source IMS framework has allowed us to focus on improving our ability to take adequate observed data and distill it into useful models through experimentation, rather than allocating resources into the manual analysis and interpretation of disjointed model predictions. 
Ellis, R and Searle R., An integrated water quality modelling framework for reporting on Great Barrier Reef catchments

\section{CONCLUSION}

The eWater source IMS catchment modelling framework provides a very flexible and useful tool to support complex modelling tasks. The Dynamic SedNet modelling components allow us to undertake a sophisticated analysis of current water quality trends and the possible impacts of future land management. The powerful reporting tools incorporated into Dynamic SedNet enable effective and efficient analysis of the modelling results. The modelling analysis being undertaken with these tools is providing a rich information source to assist in continued policy development to protect the Great Barrier Reef as well as enabling the quantification of the potential impacts of the application of these policies.

\section{REFERENCES}

Bastin, G., Scarth, P., Chewings, V., Sparrow, A., Denham, R., Schmidt, M., O'Reagain, P., Shephard, R, and B. Abbot (2012) Separating grazing and rainfall effects at regional scale using remote sensing imagery: a dynamic reference cover method. Remote Sensing of Environment 121, 443-457.

Carroll, C., Waters, D., Ellis, R., McCosker, K., Gongora, M., Chinn, C., and K. Gale (2013). Great Barrier Reef Paddock to Reef Monitoring \& Modelling Program. MODSIM 2013, Adelaide, SA.

Carroll, C., Waters, D., Vardy, S., Silburn, D.M., Attard, S., Thorburn, P., Davis, A.M., Halpin, N., Schmidt, M., Wilson, B., and A. Clark (2012). A Paddock to reef monitoring and modelling framework for the Great Barrier Reef: Paddock and catchment component. Marine Pollution Bulletin, 65(4-9): 136-149.

Cogle, A.L., Carroll, C., and B.S. Sherman (2006). Editors. The use of SedNet and ANNEX models to guide GBR catchment sediment and nutrient target Setting. Department of Natural Resources, Mines and Water.

Keating, B.A, Carberry, P.S., Hammer, G.L., Probert, M.E., Robertson, M.J., Holzworth, D., Huth, N.I., Hargreaves, J.N.G., Meinke, H., Hochman, Z., McLean, G., Verburg, K., Snow, V., Dimes, J.P., Silburn, D.M., Wang, E., Brown, S., Bristow, K.L., Asseng, S., Chapman, S., McCown, R.L., Freebairn, D.M., and C.J. Smith (2003). An overview of APSIM, a model designed for farming systems simulation. European Journal of Agronomy, 18(3-4): 267-288.

Littleboy, M. and G.M. McKeon (1997). Subroutine GRASP: Grass Production Model. Documentation of the Marcoola Version of Subroutine GRASP. Appendix 2 of "Evaluating the risks of pasture and land degradation in native pasture in Queensland”. Final Project Report for the Rural Industries Research and Development Corporation DAQ124A, pp. 76.

Newham, L.T.H., Letcher, R.A., Jakeman, A.J., and T. Kobayashi (2004). A framework for integrated hydrologic, sediment and nutrient export modelling for catchment-scale management. Environmental Modelling and Software, 19(11): 1029-1038.

Prosser IP, Rustomji P, Young B, and C. A. H. Moran (2001). Constructing river basin sediment budgets for the National Land and Water Resources Audit, Technical Report 15/01, CSIRO Land and Water, Canberra.

Rahman, J.M., Seaton, S.P., Perraud, J-M., Hotham, H., Verrelli, D.I., and J.R. Coleman (2003). It's TIME for a new environmental modelling framework. MODSIM 2003 International Congress on Modelling and Simulation(4): 1727-1732.

Rattray, D.J., Freebairn, D.M., McClymont, D., Silburn, D.M., Owens, J. and B. Robinson (2004). HOWLEAKY? The journey to demystifying 'simple' technology. In: Raine, S.R., Biggs, A.B., Menzies, N.W., Freebairn, D.M., and P.E. Tolmie (Ed.), ISCO 2004 'Conserving Soil and Water for Society: Sharing Solutions', 13th International Soil Conservation Organisation Conference. ASSSI/IECA, Brisbane.

Renard, K.G., Foster, G.A., Weesies, G.A., McCool, D.K., 1997. Predicting Soil Erosion by Water: A Guide to Conservation Planning with the Revised Universal Soil Loss Equation (RUSLE), Agriculture Handbook No. 703. USDA, Washington DC.

Searle, R.D. and R.J. Ellis (2009). Incorporating variable cover in erosion algorithms for grazing lands within catchment scale water quality models. MODSIM 2009 International Congress on Modelling and Simulation. MSSANZ and IMACS, July 2009. ISBN: 978-0-9758400-7-8.

Secretariat, R.W.Q.P.P., (2013). Reef Water Quality Protection Plan, State of Queensland, pp. 36.

Shaw, M., Silburn, D.M., Biggs, J., Thorburn, P., Whish, G., and R. Ellis (2013). Paddock scale modelling to assess agricultural management practice effectiveness in improving water quality in the Great Barrier Reef Catchments. MODSIM 2013, Adelaide, SA.

Welsh, W.D., Vaze, J., Dushmanta, D., Rassam, D., Rahman, J.M., Jolly, I.D., Wallbrink, P., Podger, G.M., Bethune, M., Hardy, M.J., Teng, J., and J. Lerat. (2013). An integrated modelling framework for regulated river systems. Environmental Modelling and Software, 39: 81-102.

Whish G. (2012). GRASP modelling of grazing systems in Great Barrier Reef catchments. Technical Report to Paddock to Reef Integrated Monitoring, Modelling and reporting program. Department of Agriculture, Fisheries and Forestry, Queensland, Australia. 